\title{
Fallopian Tube Adenocarcinoma
}

National Cancer Institute

\section{Source}

National Cancer Institute. Fallopian Tube Adenocarcinoma. NCI Thesaurus. Code C6265.

An adenocarcinoma that arises from the fallopian tube. Histologic subtypes include clear cell, endometrioid, serous, and mucinous adenocarcinoma. It spreads to adjacent organs, regional lymph nodes, and peritoneum. 